\title{
PENGARUH PEMBERIAN MINUMAN BEROKSIGEN TERHADAP KEMAMPUAN VOLUME OKSIGEN MAKSIMAL (VO2 Maks)
}

\author{
Oleh: \\ Rika Sepriani \\ DosenJurusan Pendidikan OlahragaFakultasIlmuKeolahragaan \\ Universitas Negeri Padang \\ Email: rikasepriani@fik.unp.ac.id
}

\begin{abstract}
ABSTRAK
Penelitianinibertujuanuntukmengetahuimanfaattentang produk minuman olahraga khususnyaminumanberoksigenterhadapkemampuan volume oksigenmaksimal (VO2maks). Penelitian ini bersifat eksperimental semu dengan memberikan beberapa perlakuan kepada kelompok sampel. Sampel dalam penelitian ini sebanyak 20 orang mahasiswa pendidikan olahraga berjenis kelamin laki-laki yang bukan atlet dan berbadan sehat. Data yang diperoleh dianalisis dengan menggunakan statistik uji t. Dari analisis data didapatkanterdapatperbedaan yang signifikan VO2 makssebelum dan sesudahpemberianminumanberoksigendengannilai $t_{\text {hitung }}(2,450519)<t_{\text {tabel }}(1,729)$ pada taraf signifikansi $\alpha=0,05$.
\end{abstract}

\section{Kata kunci: minuman beroksigen, VO2 maks}

\section{PENDAHULUAN}

Air minum penambah oksigen termasuk ke dalam jenis air minum dalam kemasan (AMDK) yang di dalamnya ditambahkan oksigen terlarut sehingga mengandung jumlah oksigen yang jumlahnya lebih banyak dibandingkan dengan air minum biasa (Purnama, 2004). Jumlah oksigen terlarut yang dikandung oleh air minum biasa umumnya adalah sebesar 7-12 ppm. Oleh karena itu, konsentrasi minimum oksigen terlarut di dalam produk air minum penambah oksigen ditetapkan paling sedikit sebesar 80 ppm(Guyton dan Hall, 2006).

Oksigen $\left(\mathrm{O}_{2}\right)$ adalah salah satu komponen gas dan unsur vital dalam proses metabolisme. Oksigen diperlukan sel untuk mengubah glukosa menjadi energi yang dibutuhkan untuk melakukan berbagai aktivitas, seperti aktivitas fisik, penyerapan makanan, membangun kekebalan tubuh, pemulihan kondisi tubuh, juga penghancuran beberapa racun sisa metabolisme. Seiring dengan perkembangan zaman, variasi minuman penunjang aktivitas fisik sudah lebih 
beragam diantaranya terdapat minuman beroksigeni yang sering dikonsumsi pada saat melakukan aktivitas fisik.

Oksigen dalam minuman beroksigen dimasukan dalam air melalui suatu proses dengan menggunakan tekanan, seperti halnya membuat minuman berkarbonasi (minuman bersoda) yaitu dengan memompakan $\mathrm{CO}_{2}$ ke dalam air. Oksigen yang diserap melalui membran usus halus dan usus besar dapat meningkatkan imunitas dan memperbaiki sistem sirkulasi dalam tubuh seseorang (Ellyana, dkk., 2011).Pada saat olahraga atau melakukan aktivitas fisik maka tubuh akan membutuhkan banyak oksigen yang digunakan untuk proses pembentukan energi.

Kekurangan oksigen atau gejala hipoksia juga dapat terjadi pada manusia yang melakukan aktivitas berat atau maksimum, seperti olahragawan pada waktu tertentu. Pada kondisi ini, tekanan parsial oksigen dalam darah akan menurun dan sebaliknya tekanan parsial CO2akan meningkat. Keadaan tersebut akan berdampak pada kurangnya suplai gas oksigen ke dalam sel untuk menghasilkan energi sehingga menghambat proses metabolisme sel. Gangguan tersebut akan berkolerasi dengan timbulnya berbagai gejala penyakit di dalam tubuh, seperti pusing, sesak nafas, cepat lelah, sakit otot dan sendi, mual, kekurangan energi, penurunan daya ingat, penurunan sistem imun, bahkan timbul berbagai penyakit degeneratif, termasuk kanker (Guyton dan Hall, 2006).

Daya tahan aerobik sering dilihat dari VO2maksimum yang didefinisikan sebagai laju konsumsi oksigen tertinggi yang dicapai selama atau lengkap latihan maksimal. $\quad$ VO2maksimum merupakan indikator terbaik untuk daya tahan aerob yang digunakan sebagai parameter pengukuran. $\begin{array}{lll}\text { kebugaran } & \text { fisik.. } & \mathrm{VO} 2\end{array}$ maxmerupakan suatu faktorkebugaran yang dibutuhkan manusia, baik bagi atletmaupun non atlet. Untuk kebutuhan non atlet bergunauntuk kesejahteraan kesehatan, sedangkan untuk atletselain dalam hal kesehatan yaitu dalam menunjangprestasi yang gemilang maka perlu adanyapeningkatanVO2 maxdan 
secara intensif . Latihanyang dilakukan secara aerobik tidak merubah ukuranparu- paru, tapi meningkatkan kondisi dan efisienotot pernafasan, memungkinkan penggunaankapasitas oksigen yang lebih besar (Pranata, 2015).

Tabel 1. Norma penilaian VO2 maksimum(ml/kg/min)

\section{a. Perempuan}

\begin{tabular}{|c|c|c|c|c|c|c|}
\hline $\begin{array}{c}\mathrm{Ag} \\
\mathrm{e}\end{array}$ & $\begin{array}{l}\text { Very } \\
\text { Poor }\end{array}$ & $\begin{array}{c}\text { Poo } \\
r\end{array}$ & $\begin{array}{c}\text { Fai } \\
r\end{array}$ & $\begin{array}{c}\text { Goo } \\
\mathrm{d}\end{array}$ & $\begin{array}{c}\text { Excelle } \\
\text { nt }\end{array}$ & $\begin{array}{c}\text { Superi } \\
\text { or }\end{array}$ \\
\hline $\begin{array}{c}13- \\
19\end{array}$ & $\begin{array}{c}<25 . \\
0\end{array}$ & $\begin{array}{c}25 . \\
0- \\
30 . \\
9\end{array}$ & $\begin{array}{c}31 . \\
0- \\
34 . \\
9\end{array}$ & $\begin{array}{c}35.0 \\
- \\
38.9\end{array}$ & $\begin{array}{c}39.0- \\
41.9\end{array}$ & $>41.9$ \\
\hline $\begin{array}{l}20- \\
29\end{array}$ & $\begin{array}{c}<23 . \\
6\end{array}$ & $\begin{array}{c}23 . \\
6- \\
28 . \\
9\end{array}$ & $\begin{array}{c}29 . \\
0- \\
32 . \\
9\end{array}$ & $\begin{array}{c}33.0 \\
- \\
36.9\end{array}$ & $\begin{array}{c}37.0- \\
41.0\end{array}$ & $>41.0$ \\
\hline $\begin{array}{l}30- \\
39\end{array}$ & $\begin{array}{c}<22 . \\
8\end{array}$ & $\begin{array}{c}22 . \\
8- \\
26 . \\
9\end{array}$ & $\begin{array}{c}27 . \\
0- \\
31 . \\
4\end{array}$ & $\begin{array}{c}31.5 \\
- \\
35.6\end{array}$ & $\begin{array}{c}35.7- \\
40.0\end{array}$ & $>40.0$ \\
\hline $\begin{array}{c}40- \\
49\end{array}$ & $\begin{array}{c}<21 . \\
0\end{array}$ & $\begin{array}{c}21 . \\
0- \\
24 . \\
4\end{array}$ & $\begin{array}{c}24 . \\
5- \\
28 . \\
9\end{array}$ & $\begin{array}{c}29.0 \\
- \\
32.8\end{array}$ & $\begin{array}{c}32.9- \\
36.9\end{array}$ & $>36.9$ \\
\hline $\begin{array}{l}50- \\
59\end{array}$ & $\begin{array}{c}<20 . \\
2\end{array}$ & $\begin{array}{c}20 . \\
2- \\
22 . \\
7\end{array}$ & $\begin{array}{c}22 . \\
8- \\
26 . \\
9\end{array}$ & $\begin{array}{c}27.0 \\
- \\
31.4\end{array}$ & $\begin{array}{c}31.5- \\
35.7\end{array}$ & $>35.7$ \\
\hline $\begin{array}{l}60 \\
+\end{array}$ & $\begin{array}{c}<17 . \\
5\end{array}$ & $\begin{array}{c}17 . \\
5- \\
20 . \\
1\end{array}$ & $\begin{array}{c}20 . \\
2- \\
24 . \\
4\end{array}$ & $\begin{array}{c}24.5 \\
- \\
30.2\end{array}$ & $\begin{array}{c}30.3- \\
31.4\end{array}$ & $>31.4$ \\
\hline
\end{tabular}

b. Laki-laki

\begin{tabular}{|c|c|c|c|c|c|c|}
\hline $\begin{array}{c}\mathrm{Ag} \\
\mathrm{e}\end{array}$ & $\begin{array}{l}\text { Very } \\
\text { Poor }\end{array}$ & $\begin{array}{c}\text { Poo } \\
\text { r }\end{array}$ & $\begin{array}{c}\text { Fai } \\
r\end{array}$ & $\begin{array}{c}\text { Goo } \\
\text { d }\end{array}$ & $\begin{array}{c}\text { Excelle } \\
\mathrm{nt}\end{array}$ & $\begin{array}{l}\text { Superi } \\
\text { or }\end{array}$ \\
\hline $\begin{array}{c}13- \\
19\end{array}$ & $\begin{array}{c}<35 . \\
0\end{array}$ & $\begin{array}{l}35 . \\
0- \\
38 .\end{array}$ & $\begin{array}{l}38 . \\
4- \\
45 .\end{array}$ & $\begin{array}{c}45.2 \\
- \\
50.9\end{array}$ & $\begin{array}{c}51.0- \\
55.9\end{array}$ & $>55.9$ \\
\hline
\end{tabular}

\begin{tabular}{|c|c|c|c|c|c|c|}
\hline & & 3 & 1 & & & \\
\hline $\begin{array}{l}20- \\
29\end{array}$ & $\begin{array}{c}<33 . \\
0\end{array}$ & $\begin{array}{c}33 . \\
0- \\
36 . \\
4\end{array}$ & $\begin{array}{c}36 . \\
5- \\
42 . \\
4\end{array}$ & $\begin{array}{c}42.5 \\
- \\
46.4\end{array}$ & $\begin{array}{c}46.5- \\
52.4\end{array}$ & $>52.4$ \\
\hline $\begin{array}{c}30- \\
39\end{array}$ & $\begin{array}{c}<31 . \\
5\end{array}$ & $\begin{array}{c}31 . \\
5- \\
35 . \\
4\end{array}$ & $\begin{array}{c}35 . \\
5- \\
40 . \\
9\end{array}$ & $\begin{array}{c}41.0 \\
- \\
44.9\end{array}$ & $\begin{array}{c}45.0- \\
49.4\end{array}$ & $>49.4$ \\
\hline $\begin{array}{l}40- \\
49\end{array}$ & $\begin{array}{c}<30 . \\
2\end{array}$ & $\begin{array}{c}30 . \\
2- \\
33 . \\
5\end{array}$ & $\begin{array}{c}33 . \\
6- \\
38 . \\
9\end{array}$ & $\begin{array}{c}39.0 \\
- \\
43.7\end{array}$ & $\begin{array}{c}43.8- \\
48.0\end{array}$ & $>48.0$ \\
\hline $\begin{array}{c}50- \\
59\end{array}$ & $\begin{array}{c}<26 . \\
1\end{array}$ & $\begin{array}{c}26 . \\
1- \\
30 . \\
9\end{array}$ & $\begin{array}{c}31 . \\
0- \\
35 . \\
7\end{array}$ & $\begin{array}{c}35.8 \\
- \\
40.9\end{array}$ & $\begin{array}{c}41.0- \\
45.3\end{array}$ & $>45.3$ \\
\hline $\begin{array}{c}60 \\
+\end{array}$ & $\begin{array}{c}<20 . \\
5\end{array}$ & $\begin{array}{c}20 . \\
5- \\
26 . \\
0\end{array}$ & $\begin{array}{c}26 . \\
1- \\
32 . \\
2\end{array}$ & $\begin{array}{c}32.3 \\
- \\
36.4\end{array}$ & $\begin{array}{c}36.5- \\
44.2\end{array}$ & $>44.2$ \\
\hline
\end{tabular}

Sumber: Vivian H. Heyward. 1998. Advance

Fitness Assessment \& Exercise Prescription, 3rd Edition, p48. The Physical Fitness Specialist Certification Manual, The CooperInstitute for Aerobics Research, Dallas TX.

\section{METODE PENELITIAN}

Penelitian ini tergolong penelitian eksperimental semu. Penelitian ini bertujuan untuk menentukan sejumlah perubahan yang dihasilkan oleh perlakuan.Sampel dalam penelitian ini diambil dengan menggunakan teknik purposive sampling yaitu pengambilan sampel yang dilakukan 
dengan tujuan tertentu yang memenuhi kriteria inklusi yaitu mahasiswa laki-laki, bersedia menjadi responden, berbadan sehat dan memiliki indeks masa tubuh normal sebanyak 20 orang .

Bahan-bahan yang digunakandalampenelitianiniadalahm inumanberoksigen. Alat-alat yang digunakandalampenelitianiniadalahli ntasandatar dan tidaklicin (20 meter); meteran; kaset; tape recorder/radio tape player; format test, patokuntukmenentukanjarakantaraga risstart dan finish.

Tahapanpelaksanaanpenelitia niniadalahsebagaiberikut:

a. Sebelumperlakuanpenelitian, sampeldiseleksiuntukmemper olehkesamaan (homogenitas) karakteristiksampelpenelitian meliputijeniskelamin, umur, berat badan dan tinggi badan

b. Kemudiandilakukan pretest denganmelakukanlari multi tahap (bleep test) untukmengukur VO2 maks

c. Sampeldiistirahatkan, selamaistirahatsampeldilaran gmengkonsumsimakanan/min umanenergi dan suplemen vitamin. d. Dilakukanpengukuran VO2 makskembaliyang $\quad 30$ menitsebelumnyadiberikanmi numanberoksigen.

\section{HASIL DAN PEMBAHASAN}

\section{A. HASIL}

Berdasarkan data penelitian awal (pre-test), diperoleh volume oksigen terendah 26,2 dan tertinggi 44,8. Dari analisis data didapatkan nilai volume oksigen maksimal $\left(\mathrm{VO}_{2}\right.$ maks) rata-rata sebesar 35,77, standar deviasi 5,14, Median 37. Distribusi frekuensi tampak pada tabel berikut ini:

Tabel 2. Distribusi Frekuensi Volume Oksigen Mkasimal (VO2 maks) Pretest

\begin{tabular}{|c|c|c|}
\hline Kelas Interval & Frekuensi Absolut & Frekuensi Rel \\
\hline$<33,0$ & 6 & 30 \\
\hline $33,0-36,4$ & 4 & 20 \\
\hline $36,5-42,4$ & 8 & 40 \\
\hline $42,5-46,4$ & 2 & 10 \\
\hline $46,5-52,4$ & 0 & 0 \\
\hline$>52,4$ & 0 & 0 \\
\hline Jumlah & 20 & 100 \\
\hline
\end{tabular}

Dari tabel diatas dapat dilihat dari 20 orang sampel penelitian nilai volume oksigen maksimal (VO2 maks) yang paling banyak terdapat pada kelas interval < 
$36,5-42,4$ sebanyak 8 orang $(40 \%)$ yang berada pada klasifikasi cukup, kelas interval $<33,0$ sebanyak 6 orang (30\%) pada klasifikasi sangat kurang, kelas interval 33,0-36,4 sebanyak 4 orang (20\%) pada klasifikasi kurang, kelas interval 42,5-46,4 sebanyak 2 orang (10\%) pada klasifikasi baik dan tidak ada satu orangpun yang berada pada kelas interval 46,5-52,4 dan >52,4 pada klasifikasi baik sekali dan sangat baik sekali. Untuk lebih jelasnya dapat dilihat pada histogram berikut ini:

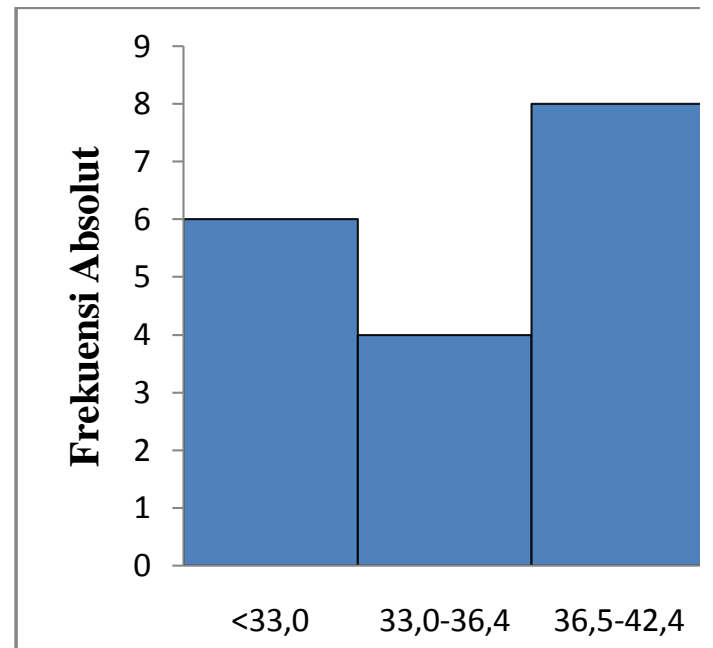

Kelas I

Histogram Volume Oksigen

Maksimal (VO2 maks) Pretest

Minuman Beroksigen

Setelah diberikan minuman beroksigen didapatkan nilai volume oksigen maksimal (VO2 maks) terendah 27,6 dan tertinggi 50,4. Dari analisis data didapatkan nilai volume oksigen maksimal $\left(\mathrm{VO}_{2}\right.$ maks) ratarata sebesar 37,78, standar deviasi 5,38, Median 37. Distribusi frekuensi tampak pada tabel berikut ini:

Tabel 3. Distribusi Frekuensi Volume Oksigen Mkasimal (VO2 maks) Postest

\begin{tabular}{|c|c|r|}
\hline Kelas Interval & Frekuensi Absolut & Frekuensi R \\
\hline$<33,0$ & 2 & 10 \\
\hline $33,0-36,4$ & 6 & 30 \\
\hline $36,5-42,4$ & 7 & 35 \\
\hline $42,5-46,4$ & 4 & 20 \\
\hline $46,5-52,4$ & 1 & 5 \\
\hline$>52,4$ & 0 & 0 \\
\hline Jumlah & 20 & 10 \\
\hline
\end{tabular}

Dari tabel diatas dapat dilihat dari 20 orang sampel penelitian nilai volume oksigen maksimal (VO2 maks) yang paling banyak terdapat pada kelas interval < $36,5-42,4$ sebanyak 7 orang $(35 \%)$ yang berada pada klasifikasi cukup, kelas interval 33,0-36,4 sebanyak 6 orang (30\%) pada klasifikasi kurang, kelas interval 42,5-46,4 sebanyak 4 orang (20\%) pada klasifikasi baik, kelas interval $<33,0$ sebanyak 2 orang (10\%) pada klasifikasi sangat kurang dan pada kelas interval 46,552,4 sebanyak 1 orang (5\%) pada 
klasifikasi baik sekali dan tidak ada satu orangpun yang berada pada kelas interval $>52,4$ pada klasifikasi sangat baik sekali. Untuk lebih jelasnya dapat dilihat pada histogram berikut ini:

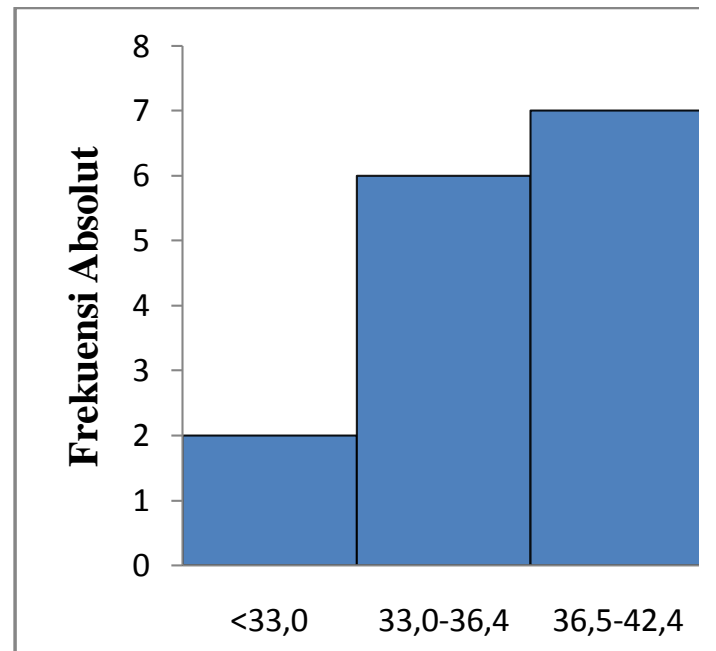

Kelas I

Histogram Volume Oksigen

Maksimal (VO2 maks) Postest

Minuman Beroksigen

\section{Nilai Rata-Rata Volume Oksigen} maksimum Pretest dan Posttest

$$
\text { Pada penelitian ini }
$$

pengukuran VO2 maksimum pada subjek penelitian dilakukan sebelum dan sesudah diberikan minuman beroksigendengan menggunakan tes multi tahap atau bleep test. Hasil pengukuran $\quad \mathrm{VO} 2$ maksimum sebelum diberikan minuman beroksigen memiliki nilai rata-rata VO2 maks 35,77 . Tiga puluh menit setelah pemberian minuman beroksigendilakukan bleep test pada subjek dan diukur VO2 maksimum. Hasil pengukurannya menunjukkan terjadi peningkatan VO2 maksimum dimana nilai rata-rata $\mathrm{VO} 2$ maksimum 37,78 .

Untuklebihjelasnyadapatdilihat pada tabeldibawahini:

Tabel 4. Nilai rata-rata $\mathrm{VO} 2$ maksimum

\begin{tabular}{|l|c|c|}
\hline \multirow{2}{*}{ No. } & \multicolumn{2}{|c|}{ Nilai rata-rata VO2 maksimum } \\
\cline { 2 - 3 } & Pretest & Posttest \\
\hline 1. & 35,77 & 37,78 \\
\hline
\end{tabular}

\section{Untuklebihjelasnyanilai}

rata-rata volume oksigenmaksimum (VO2 maks) sebelum dan sesudahperlakuandapatdilihat pada histogram dibawahini: 


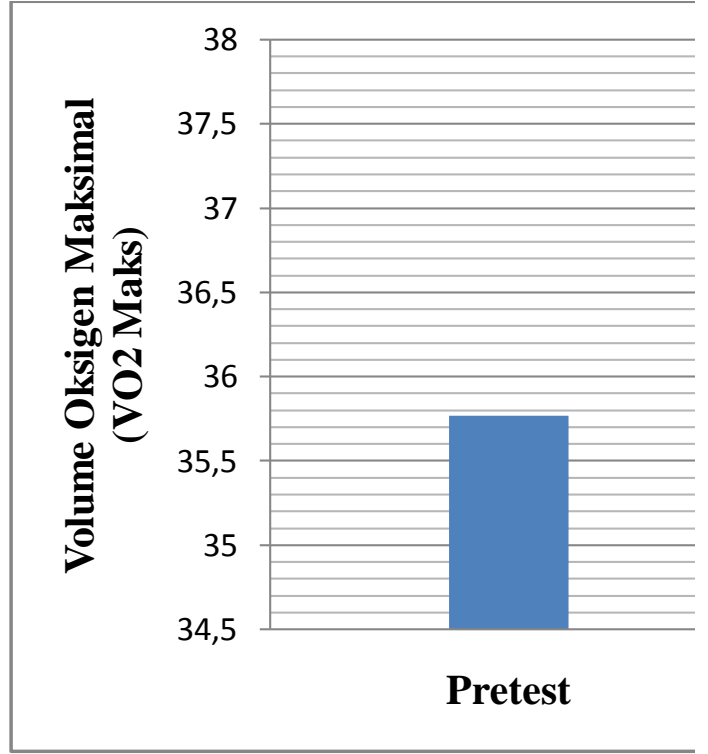

Histogram Nilai rata-rata VO2 maks

\section{B. PEMBAHASAN}

\section{Kapasitas aerobik}

ditentukan oleh kemampuan organ dalam tubuh mengangkut oksigen untuk memenuhi seluruh jaringan (Sukadiyanto, 2011). Daya tahan aerob sering dilihat dari $\mathrm{VO} 2$ maksimum yang didefinisikan sebagai laju konsumsi oksigen tertinggi yang dicapai selama atau lengkap latihan maksimal.Nilai-nilai untuk VO2 Max adalah kemampuan seseorang untuk menyediakan energi untuk otot-otot melalui metabolisme aerobik. Konsumsi oksigen mengacu pada jumlah oksigen yang digunakan selama latihan. Jumlah tersebut menandai dengan jumlah oksigen yang diambil selama latihan. Konsumsi oksigen pada umumnya dinyatakan menurut banyaknya liter atau mililiter oksigen yang digunakan oleh tubuh selama masing-masing latihan. Tingkat kebugaran seseorang berhubungan erat dengan VO2 Max seseorang dengan kapasitas aerobik maksimal berarti memiliki VO2 Max yang tinggi maka tingkat kebugaran aerobiknya juga tinggi. Dengan ketahanan kardiorespirasi yang baik maka akan mampu melakukan kerja maskimal dalam waktu yang lama (Nurhasan, 2005).

Oksigen (O2) adalah salah satu komponen gas dan unsur vital dalam proses metabolisme. Oksigen diperlukan sel untuk mengubah glukosa menjadi energi yang dibutuhkan untuk melakukan berbagai aktivitas, seperti aktivitas fisik, penyerapan makanan, membangun kekebalan tubuh, pemulihan kondisi tubuh, juga penghancuran beberapa racun sisa metabolisme (Nikmawati, 2008). Seiring dengan perkembangan zaman, variasi minuman sudah lebih beragam diantaranya terdapat minuman beroksigen yang sering dikonsumsi pada saat melakukan 
aktivitas fisik. Oksigen dalam minuman beroksigen dimasukan dalam air melalui suatu proses dengan menggunakan tekanan, seperti halnya membuat minuman berkarbonasi (minuman bersoda) yaitu dengan memompakan $\mathrm{CO} 2$ ke dalam air. Oksigen yang diserap melalui membran usus halus dan usus besar dapat meningkatkan imunitas dan memperbaiki sistem sirkulasi dalam tubuh seseorang (Nikmawati, 2008).

Penelitian ini dilakukan di lapangan sepak bola FIK UNP terhadap mahasiswa Jurusan Pendidikan Olahraga Fakultas Ilmu Keolahragaan Universitas Negeri Padang yang bukan atlet dan berbadan sehat. Pengukuran VO2 maksimum pada subjek penelitian dilakukan sebelum dan sesudah diberikan minuman beroksigen dengan menggunakan tes multi tahap atau bleep test. Hasil pengukuran VO2 maksimum sebelum diberikan minuman beroksigen menunjukkan nilai rata-rata $\mathrm{VO} 2$ maks 35,77 . Kemudian subjek diistirahatkan selama 10 hari dan diukur kembali nilai VO2 maks dimana diberikan minuman beroksigen tiga puluh menit sebelum pengukuran dan didapatkan nilai VO2 maks 37,78.

Sebelumdilakukanpenguj ianstatistikdilakukan uji persyaratananalisisuji normalitas dengan uji Liliefors. Berdasarkan uji normalitas diperoleh harga $\mathrm{L}_{0}$ dan $\mathrm{L}_{\mathrm{t}}$ pada taraf nyata 0,05 untuk $\mathrm{n}=20$. Kriteria pengujian $\mathrm{L}_{0}<\mathrm{L}_{\mathrm{t}}$ maka sampel berasal dari populasi yang terdistribusi normal. Dari hasil pengujian statistik terdapat perbedaan yang signifikan nilai VO2 maksimum sebelum pemberian minuman beroksigen dengan sesudah pemberian minuman beroksigen. Hal ini dapat dilihat dari nilai $t_{\text {hitung }}$ $(2,450519)<t_{\text {tabel }}(1,729)$ pada taraf signifikansi $\alpha=0,05$. Hal ini sejalan dengan penelitian yang dilakukan oleh Baker JD, Carey DG dan Beck BK melaporkan bahwa terhadap 8 atlet yang mengonsumsi air beroksigen dapat terjadi peningkatan signifikan terhadap performa, kekuatan daya tahan, dan kecepatan.

Seperti halnya zat-zat makanan, oksigen pun dapat masuk dan diserap oleh tubuh melalui saluran pencernaan (Rhoades RA, 2009). Penyerapan oksigen secara cepat terjadi di dalam usus. Absorbsi 
minuman beroksigen masuk ke kapiler membran mukosa saluran cerna kemudian ke vena portal dan masuk ke sirkulasi hati serta ke seluruh sirkulasi tubuh. Peningkatan oksigen dalam darah ini akan mencapai organ tubuh mengikuti jalur hematogen oleh hemoglobin dari paru-paru ke jaringan. Menurut Jenskins et al (2002) penyerapan air beroksigen tinggi di dalam usus membutuhkan waktu 15 menit dan mengacu pada proses absorbsi makanan yang membutuhkan waktu 4 jam (Jenskins A, 2002). Penyerapan oksigen di dalam usus halus dimungkinkan karena bagian ini hanya dilapisi oleh sel-sel epitel silindris lapis tunggal. Oksigen akan masuk dengan cara difusi pasif melalui membran epitel yang membatasi lumen usus halus (Zakaria, 2005).

Oksigen dari minuman beroksigen yang masuk ke dalam kapiler darah digunakan untuk proses oksidasi zat-zat makanan didalam tubuh untuk menghasilkan energi. Energi yang diperoleh dapat digunakan untuk melakukan berbagai aktivitas fisik.

\section{KESIMPULAN}

1. Nilai rata-rata volume oksigenmaksimum (VO2 maks) awalyaitu 35,77

2. Nilai rata-rata volume oksigenmaksimum (VO2 maks) setelahdiberikanminu manberoksigenyaitu 37,78

3. Nilai volume oksigenmaksimum (VO2 maks) memilikiperbedaan yang bermaknasecarastatisti ksebelum (pretest) dan sesudah (posttest) pemberianminumanbe roksigen.

\section{DAFTAR PUSTAKA}

Ellyana NS, Sarosa H, Hussaana A. 2011. Perbedaan Pengaruh Air Beroksigen Tinggi dengan Air Mineral Terhadap Saturasi Oksigen dan PH Urin. Sains Medika Vol 3(2);162-7. 
Guyton, A.C., Hall J.E. 2006.BukuAjar Fisiologi Kedokteran, Edisi ke-11. Jakarta: EGC.

Jenskins A, Moreland M, Waddell TB,Fernhall B. 2002. Effects of Oxygenated Water In Percent Oxygen Saturatian andPerforming During Exercise. Med Sci Sport Exerc, 33:1-14.

Nikmawati EE. 2008. Pentingnya Air Dan Oksigen Bagi Kesehatan Tubuh Manusia. Bandung: Universitas Pendidikan Indonesia.

Nurhasan. 2005. Aktivitas Kebugaran. Jakarta: Depdiknas.

Pranata Aji Kusuma. 2015. Analisis Daya Tahan Aerobik Maksimal (Vo2max) dan Anaerobik pada AtletBulutangkis Usia 1114 Tahun PB. Bintang Timur Surabaya Menjelang KejurnasJatim 2014. Jurnal Kesehatan Olahraga Vol. 3 No. 3: 444-451.

Purnama, L. 2004. Teknologi Produksi Air Beroksigen. Materi Presentasi dalam Diskusi Ilmiah Air Minum Penambah Oksigen. R\&K Health Living dan FATETA IPB, Bogor.

Rhoades RA, Bell DR. 2009. Medical
Phisiology.Maryland:

Lippincott Williams \& Wilkins.

Sukadiyanto.2011 . Pengantar Teori dan Metodologi Melatih Fisik. Bandung: CV. Lubuk Agung.

Vivian H. Heyward. 1998. Advance Fitness Assessment \& Exercise Prescription, 3rd Edition, p48. The Physical Fitness Specialist Certification Manual, Dallas TX: The CooperInstitute for Aerobics Research.

Zakaria, F. R. 2005. Air Minum Beroksigen Tinggi Aman untuk Dikonsumsi.Tulisan Ilmiah.Bogor:

$\mathrm{R} \& \mathrm{~K}$ Beverages. 